Ihab Kaddoura, Joschka Bischoff, Kai Nagel

\title{
Towards welfare optimal operation of innovative mobility concepts: External cost pricing in a world of shared autonomous vehicles
}

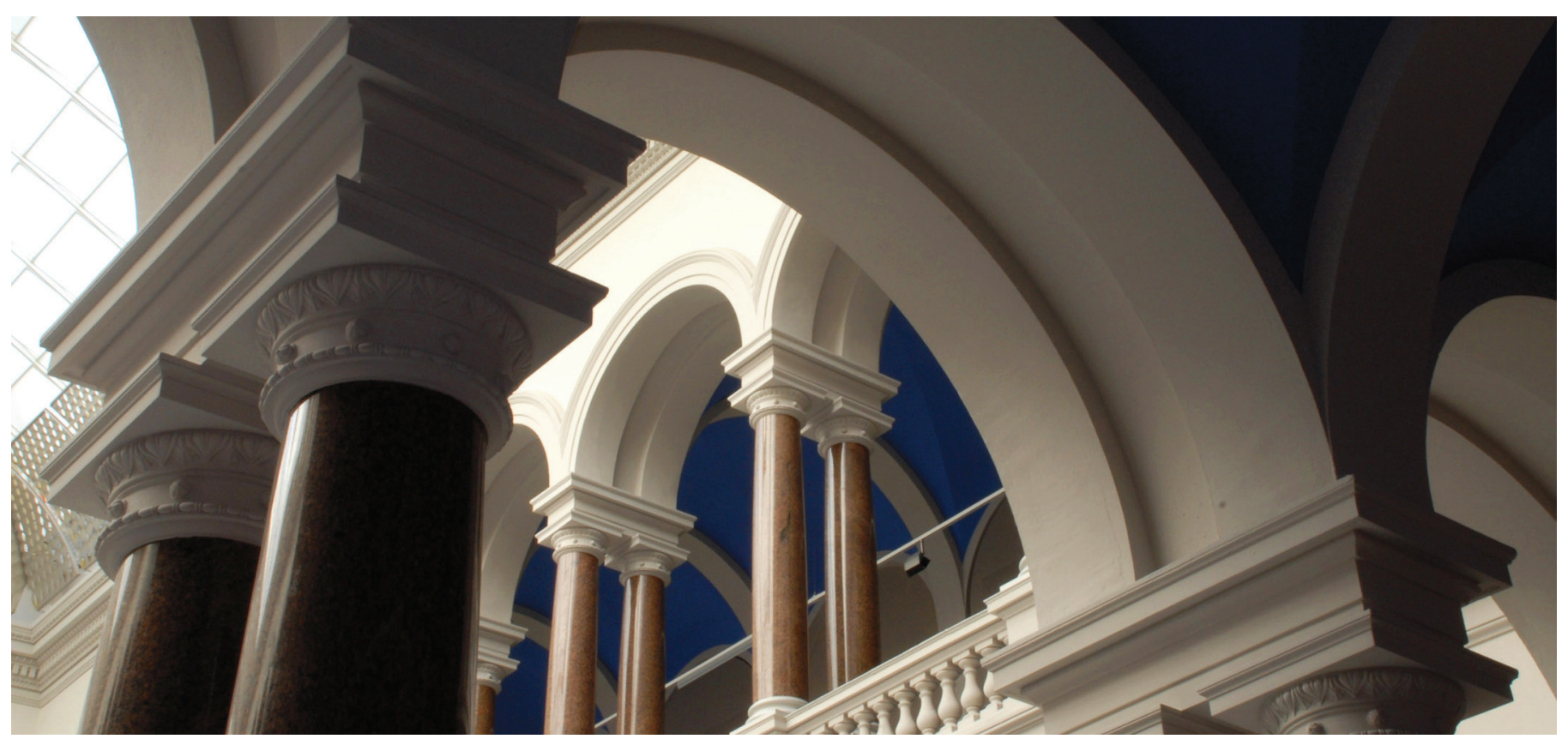

I. Kaddoura, J. Bischoff, K. Nagel; Towards welfare optimal operation of innovative mobility concepts: External cost pricing in a world of shared autonomous vehicles. presented at hEART 2017 - 6th Symposium of the European Association for Research in Transportation, September 12-24, 2017. 


\title{
Towards welfare optimal operation of innovative mobility concepts: External cost pricing in a world of shared autonomous vehicles
}

\author{
Ihab Kaddoura*, Joschka Bischoff, Kai Nagel \\ Technische Universität Berlin \\ Department of Transport Systems Planning and Telematics \\ Salzufer 17-19; 10587 Berlin; Germany \\ * Corresponding author (e-mail: kaddoura@vsp.tu-berlin.de)
}

February 20, 2019

\begin{abstract}
Autonomous vehicles (AV) create new opportunities to traffic planners and policymakers. In the case of shared autonomous vehicles (SAVs), dynamic pricing, vehicle routing and dispatch strategies may aim for the maximization of the overall system welfare instead of the operator's profit. In this study, an existing congestion pricing methodology is applied to the SAV transport mode. On the SAV operator's side, the routing- and dispatch-relevant cost are extended by the time and link-specific congestion charge. On the users' side, the congestion costs are added to the fare. Simulation experiments are carried out for Berlin, Germany in order to investigate the impact of SAVs and different pricing setups on the transport system. For the pricing setup, where SAV users only pay the base fare and there is no congestion charge added to the user costs, the model predicts an SAV share of $17.7 \%$ within the inner-city Berlin service area. The level of traffic congestion increases, air pollution levels decrease and noise levels slightly increase in the inner-city area. The SAV congestion charge pushes users from SAVs to the walk, bicycle and conventional (driver-controlled) private car (CC) mode. The latter effect is avoided by applying the same congestion charge also to CC users. Overall, this study highlights the importance to control both, the SAV and CC mode in order to improve a city's transport system.
\end{abstract}




\section{Introduction and problem statement}

In the last few years, research on autonomous vehicles (AVs) has increased substantially and several companies have started the development and real-world application of AVs (Harris, 2015; Hsu, 2016). A broad market introduction of shared autonomous vehicles (SAVs), also referred to as autonomous taxis or autonomous car-sharing, is expected in the coming years. According to most studies, one SAV is capable to replace up to approximately 10 conventional (driver-controlled) private car (CC) trips at a high service quality; the total mileage is found to increase caused by empty trips to pick up passengers (Spieser et al., 2014; Fagnant and Kockelman, 2014; Martinez et al., 2014; Burghout et al., 2015;

Bischoff and Maciejewski, 2016a). In the case of pooling (ride sharing) and depending on the fleet size, even more CC trips may be replaced by one SAV and total mileage may decrease (see e.g. Burghout et al., 2015).

Analyzing the overall welfare effects of introducing an SAV mode needs to account for both, the transport users and operators. On the operator's side, several cost components need to be considered, e.g. depreciation, fuel, cleaning, navigation fees, maintenance and wear (see e.g., Bösch et al., 2018; Litman, 2017a). The estimation of average vehicle costs is addressed in several studies with lower-bound estimates in the range of 0.30 to 0.38 EUR per passenger-km (Bösch et al., 2018; Trommer et al., 2016) and upper-bound estimates between 0.40 and 2.00 EUR per passenger-km (Litman, 2017a). Bösch et al. (2018) find the average costs per passenger-km to be lower for SAVs compared to CCs or private AVs. In contrast, Litman (2017a) estimates SAVs to cost more than CCs or private AVs.

On the users' side, increased total mileage may translate into a higher level of traffic congestion which increases generalized travel costs. The increase in total mileage may result from empty pick-up trips, vehicle relocations (Fagnant and Kockelman, 2016), mode shift effects and newly generated trips (Truong et al., 2017; Harb et al., 2018). On the other hand, SAVs are expected to increase the level of comfort and, thus, to decrease the marginal costs of traveling. The value of travel time savings (VTTS) is expected to be reduced by 30-35\% (Litman, 2017b; Childless et al., 2015). Furthermore, travel time may be saved by eliminating parking search (Litman, 2017a). Also, a more fluent flow of autonomous vehicles, platooning as well as intelligent routing may reduce traffic congestion (Fagnant and Kockelman, 2015; Litman, 2017a). Shared vehicles are expected to reduce 
car ownership (Litman, 2017a) which translates into a reduction of daily fixed costs for owning a CC (or a private AV). By avoiding the human error, AVs have the potential to reduce accident costs (Fagnant and Kockelman, 2015; Litman, 2017a). In case SAVs are considered to be non-electric vehicles, on the one hand, the increase in total mileage may increase air pollution costs (Litman, 2017a). On the other hand, eliminated parking search, reduced cold starts and environmental friendly vehicles (shortened vehicle lifespan) may decrease air pollution costs (Fagnant and Kockelman, 2014). Furthermore, (S)AVs may reduce the demand for nearby parking which allows for a new usage of public space (Fagnant and Kockelman, 2015). On the other hand, additional space may be required for pick-up and drop-off activities.

Considering mobility as a "normal good", lower travel costs are expected to increase total vehicle-kilometers, i.e. the number of trips and/or the trip distances (see e.g., Litman, 2017a). The expected increase in traffic may result in an inefficient usage of resources and a loss in system welfare. This study investigates optimal price setting strategies for SAVs and CCs in order to prevent an excessive use of transport resources. Following the concept of Pigouvian taxation, the system welfare is maximized by internalizing so-called external effects (Pigou, 1920). By adding the external costs to the generalized travel costs, the decision-relevant travel costs are corrected and reflect the full costs associated with the usage of transport resources. For decisions which routes to take, marginal external costs vary with the road segment and time of day. Consequently, a first-best optimal tolling scheme to optimize the road usage may be difficult to be fully understood by the transport users, resulting in failing incentives and welfare losses. Furthermore, the required tolling technology may be very costly. A more simplified second-best tolling scheme may reduce tolling costs and be more comprehensible for the transport users, however, also involve a loss in welfare compared to the first-best solution. A world with (S)AVs creates new opportunities to traffic planners and policy-makers. Instead of providing incentives to private car users by means of optimal pricing, traffic management may directly control the AV operation. In particular, in the case of SAVs, dynamic vehicle routing and dispatch strategies may aim for the maximization of the overall system welfare instead of the operator's profit. This offers a crucial advantage over existing pricing schemes for CCs. For transport users' decisions to use the SAV mode or an alternative mode of transportation, trip-specific marginal external costs may be added to the base fare paid by SAV users. 
There are several studies in which the Pigouvian taxation principle is applied in the context of road traffic (see e.g. Vickrey, 1969; Arnott et al., 1993; Verhoef and Small, 2004; Kaddoura, 2015; Kaddoura et al., 2017b) or public transport (see e.g. Turvey and Mohring, 1975; Kraus, 1991; Kaddoura et al., 2015). External cost pricing in the context of innovative mobility concepts, e.g. (S)AVs, is investigated to a lesser extent. Sharon et al. (2017) present a welfare improving tolling approach and discuss its potentials in the context of AV technology, i.e. computer-controlled route choice, however, neglect transport users' mode choice decisions. Most existing studies neglect transport users mode choice reactions and assume a fixed amount of SAV trips (see e.g. Maciejewski and Bischoff, 2015; Bischoff and Maciejewski, 2016a,b; Fagnant and Kockelman, 2016). In contrast, Liu et al. (2017) account for transport users' mode choice reactions and investigate different fare levels. The SAV fares are, however, static and not related to the level of traffic congestion. Liu et al. (2017) also discuss the impact of SAVs on air pollutant emissions and estimate a reduction of emitted air pollutants, however, without looking into the spatial effects.

The present study picks up the lack of research and investigates optimal price setting strategies for SAV and CC users. An agent-based simulation framework is used to model transport users' reactions to a newly introduced SAV mode in Berlin, Germany. Transport users are enabled to adjust the mode of transportation, departure time and transport route. To the best of the authors' knowledge, this is the first study in which congestion pricing strategies are investigated in the context of SAVs and transport users' mode choice decisions are explicitly taken into account. Furthermore, this study analyzes the impact of SAVs and the pricing strategy on the environment, i.e. air pollution and noise levels, and provides a detailed look into the mode switch effects.

The remainder of this paper is organized as follows. Sec. 2 briefly describes the agentbased simulation framework and presents the SAV pricing methodology. Sec. 3 describes the Berlin case study, simulation setup and experiments. Sec. 4 describes the simulation results, Sec. 5 provides the discussion and Sec. 6 concludes this study. 


\section{Methodology}

\subsection{SAV optimization approach}

This study proposes an optimal SAV operation approach which builds on the Pigouvian taxation principal, i.e. the internalization of congestion costs. The congestion charge is computed for each road segment and $900 \mathrm{sec}$ time interval. The computation of dynamic congestion prices follows the iterative interval-based list pricing methodology described in (Kaddoura and Nagel, 2019). A discrete Proportional Controller is applied which sets the congestion charge proportionally to the average delay. The trip-specific costs are then taken into account by the SAV operator and users:

- On the SAV operator's side, the routing- and dispatch-relevant cost are extended by the time and link-specific congestion costs.

- On the user side, the trip-related congestion costs caused by the SAV are added to the base fare to be charged from the SAV user. The trip-related congestion costs also include the external costs incurred during the pick-up trip.

SAV operators are allowed to adjust their vehicle dispatching and routing in order to avoid the congestion charge. Transport users are enabled to adjust their mode of transportation, their departure time as well as their transport route. In each iteration the road- and timespecific congestion cost term is (re-)computed based on the updated delay level applying the method of successive averages.

\subsection{Agent-based transport simulation framework}

MATSim overview The proposed optimization approach uses the agent-based and dynamic transport simulation framework MATSim ${ }^{1}$ (Horni et al., 2016). In MATSim, each transport user is modeled as an individual agent. Transport demand adapts to the transport supply (road network, SAV availability, tolls, fares) applying an evolutionary iterative approach involving the following three steps:

1. The traffic flow is simulated. SAVs and CCs interact on the same network applying a queue model which accounts for dynamic congestion and spill-back effects.

\footnotetext{
${ }^{1}$ Multi-Agent Transport Simulation, see www.matsim.org
} 
2. Each agent evaluates his/her daily (travel) behavior taking into consideration (i) the time spent performing an activity and (ii) travel-related costs, e.g. mode-specific fixed cost and travel time costs, tolls, fares.

3. The agents are enabled to adjust their travel behavior, i.e. switch to another route or mode of transportation.

MATSim SAV module The simulation of shared autonomous vehicles uses an existing module for dynamic vehicle routing problems (Maciejewski, 2016; Maciejewski et al., 2017) and an existing module for the simulation of autonomous vehicles (Bischoff and Maciejewski, 2016a). SAV users need to order an SAV once they have left their activity location, wait for an available SAV to arrive, get on the SAV and get off the SAV at the destination. SAVs interact with each other vehicles (SAVs and CCs) and may get stuck in traffic.

\section{Case study and simulation experiments}

\subsection{Case study: Greater Berlin area}

The transport supply side contains all roads and public transit lines in the Greater Berlin area. Travel demand consists of commuters and non-commuters using the car, public transit, bicycle, ride and walk mode. The synthetic population is calibrated against realworld traffic data, i.e. car counts, modal split infas and DLR (2010) and trip-distances Ahrens (2009). To speed up computational performance, in this study, a $10 \%$ sample is used and the SAV fleet size and road capacities are accordingly reduced. A detailed description of the applied case study is provided in Ziemke et al. (2019). The Berlin case study is publicly available on https://github.com/matsim-vsp/matsim-berlin (release 5.2).

\subsection{SAV setup: Adding SAVs as an additional mode of transportation}

A fleet of 10,000 SAVs is added to the existing modes of transportation and may be used for trips starting and ending within the service area. The service area is set to the inner-city Berlin area (see Fig. 1). In the first iteration, all vehicles are randomly distributed in the service area, in all further iterations, vehicles remain on the link where the last passenger 
was dropped off. The vehicle fleet size is set in a way that there are no capacity-related effects, i.e. there are always vehicles available to serve all passengers.

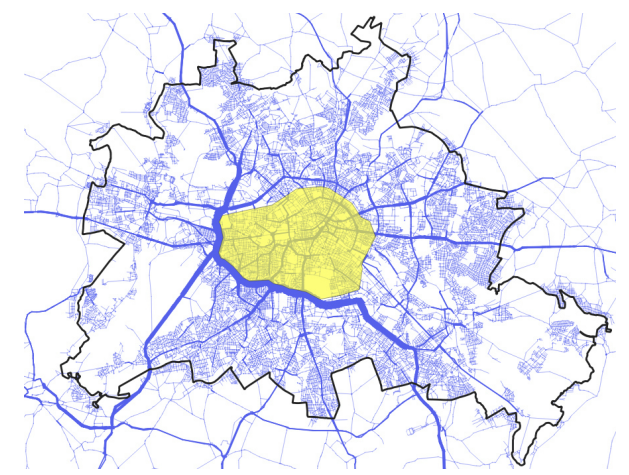

Figure 1: Case study: Greater Berlin Area. Black line: Berlin city boundary. Blue lines: Road network, the line width corresponds to the relative traffic volume in the base case. Yellow area: SAV service area.

\subsection{Simulation experiments}

The following simulation experiments are carried out.

- Base case (bc-0): There is no SAV mode and there is no congestion charge applied to any transport mode.

- SAV base fare pricing (SAV-0): The SAV mode is added as an additional mode of transportation (see Sec. 3.2). SAV users only have to pay the base fare. There is no congestion charge applied to any transport mode.

- SAV base fare + external cost pricing (SAV-1): The SAV mode is added as an additional mode of transportation (see Sec. 3.2). The congestion charge is applied to the SAV mode only. That is, SAV users have to pay the base fare plus road and time-specific congestion prices.

- SAV base fare + external cost pricing; CC external cost pricing (SAV-2): The SAV mode is added as an additional mode of transportation (see Sec. 3.2). The congestion charge is applied to both the SAV and CC mode. That is, SAV users have to pay the base fare plus road and time-specific congestion prices and also CC users have to pay road and time-specific congestion prices. 


\subsection{Transport users' choice dimensions}

All transport users are allowed to change their transport routes and departure times in order to avoid traffic congestion or toll payments. In addition, all users are allowed to change their mode of transportation. For each sub-tour, i.e. trip chains starting and ending at the same activity location, the transport mode may be changed to only car, only bicycle (chain-based modes) or a combination of public transit and walk. The ride mode is fixed, i.e. transport users are not enabled to switch from or to the ride mode. Each agent's choice sets is limited to 5 travel plans. All simulation experiments are run for a total of 200 iterations. During choice set generation (first 160 iterations), in each iteration the share of agents who change their mode, route and departure time is set to $10 \%, 5 \%$ and $5 \%$. In the final 40 iterations, all agents select from their choice sets based on a multinomial logit model.

\subsection{Transport modes}

CC (Conventional Car) CC users' travel times result from the simulated traffic flows, including the interaction of SAVs and CCs.

SAV (Shared Autonomous Vehicle) The SAV fleet size is set to 10,000 SAVs (scaled up to $100 \%$ ). The SAV service area is set to the inner-city Berlin area, a trip request starting and/or ending outside the service area is rejected and the agent gets stuck. In this study, the service does not allow for pooling (ride-sharing). In the first iteration, the vehicles are randomly distributed in the inner-city Berlin area. Then, vehicles remain on the link where the last drop off took place. The pick-up duration is set to 2 minutes, the drop off duration is set to 1 minute. SAVs interact with other SAVs as well as CCs. Assuming mixed traffic conditions, traffic flow parameters for SAVs are considered to be equal to $\mathrm{CC}$.

Public Transit Travel times within the public transport mode result from walking times from and to the transit stop, waiting times and in-vehicle times based on the schedule. In this simulation setup, buses and tramways do not interact with SAVs, CCs or bicycles. 
Walk, Bicycle, Ride The walk, bicycle and ride mode are simulated in a simplified way, i.e. teleported from one activity to the next one. That is, transport users do not interact with each other or users of other modes. For walk and bicycle, the travel times are computed based on a mode-specific speed (walk: $4 \mathrm{~km} / \mathrm{h}$; bicycle: $12 \mathrm{~km} / \mathrm{h}$ ) and a trip distance resulting from the beeline distance and a beeline distance factor (walk: 1.5; bicycle: 1.4). For ride, the travel time is computed based on the least cost network route taking into consideration the (congested) car travel time.

\subsection{Cost parameters}

System welfare is computed as

$$
W=V+\Pi+C_{\text {toll }}^{C C}+C_{\text {toll }}^{S A V o}
$$

where $V$ is the user benefits, $\Pi$ is the profit of the SAV operator, and $C_{\text {toll }}^{S A V o}$ and $C_{\text {toll }}^{C C}$ are the toll revenues earned by the regulator, e.g. the state. The user benefits are

$$
V=\sum_{i}\left(V_{i, a c t i v i t y} \cdot \beta_{\text {money }}^{-1}-C_{i, \text { travel }}\right)
$$

where $i$ denotes the person, $V_{i, \text { activity }}$ is the positive utility from performing activities, beta $_{\text {money }}$ is the marginal utility of money and $C_{i, \text { travel }}$ are the travel related costs computed as

$$
\begin{aligned}
C_{i, \text { travel }}=c_{\text {trip }}^{C C} & \cdot n_{i}^{C C}+c_{k m}^{C C} \cdot d_{i}^{C C}+c_{\text {hour }}^{C C} \cdot t_{i}^{C C}+C_{i, t o l l}^{C C} \\
& +r_{\text {day }}^{S A V u}+c_{\text {trip }}^{S A V u} \cdot n_{i}^{S A V u}+c_{k m}^{S A V u} \cdot d_{i}^{S A V u}+c_{\text {hour }}^{S A V u} \cdot t_{i}^{S A V u}+C_{i, \text { fare }}^{S A V u}
\end{aligned}
$$

The profit $\Pi$ is computed as

$$
\Pi=C_{\text {fare }}^{S A V u}-C_{\text {toll }}^{S A V o}-C^{S A V o},
$$

where $C_{\text {fare }}^{S A V u}$ are the revenues, $C_{\text {toll }}^{S A V o}$ are the toll payments paid by the operator and $C^{S A V o}$ are the SAV operating costs. Inserting Eq. 4 into Eq. 1 yields the following:

$$
W=V+C_{\text {fare }}^{S A V u}+C_{\text {toll }}^{C C}-C^{S A V o}
$$

The mode-specific cost parameters are given in Tab. 1. 
Table 1: Cost parameters

\begin{tabular}{|c|c|c|c|}
\hline $\mathrm{CC}$ & $\begin{array}{l}\text { trip-related fixed cost } \\
\text { kilometer-based operating cost rate } \\
\text { private time cost } \\
\text { total congestion and noise road charges }\end{array}$ & $\begin{array}{l}c_{t r i p}^{C C} \\
c_{k m}^{C C} \\
c_{h}^{C C} \\
C_{\text {toll }}^{C C}\end{array}$ & $\begin{array}{l}\text { 1.5 EUR per trip (Ziemke et al., 2019) } \\
0.20 \text { EUR per vehicle-kilometer (Ziemke et al., } \\
2019 \text { ) } \\
=\text { beta } a_{\text {perf }} \text { (opportunity cost of time) }=6.0 \text { EUR } \\
\text { per person-hour (Ziemke et al., 2019) } \\
\text { see Sec. } 2.1\end{array}$ \\
\hline Walk & $\begin{array}{l}\text { trip-related fixed cost } \\
\text { private time cost }\end{array}$ & $\begin{array}{l}c_{\text {trip }}^{\text {walk }} \\
c_{h}^{\text {walk }}\end{array}$ & $\begin{array}{l}0.00 \text { EUR per trip (Ziemke et al., 2019) } \\
=\text { beta } a_{\text {perf }}=6.0 \text { EUR per hour (Ziemke et al., } \\
2019)\end{array}$ \\
\hline Bicycle & $\begin{array}{l}\text { trip-related fixed cost } \\
\text { private time cost }\end{array}$ & $\begin{array}{l}c_{\text {trip }}^{\text {bike }} \\
c_{h}^{\text {bike }}\end{array}$ & $\begin{array}{l}1.85 \text { EUR per trip (Ziemke et al., 2019) } \\
=\text { beta } a_{\text {perf }}=6.0 \text { EUR per hour (Ziemke et al., } \\
2019 \text { ) }\end{array}$ \\
\hline PT & $\begin{array}{l}\text { trip-related fixed cost } \\
\text { private time cost }\end{array}$ & $\begin{array}{l}c_{\text {trip }}^{\text {fast } P T} \\
c_{h}^{\text {fastPT }}\end{array}$ & $\begin{array}{l}0.60 \text { EUR per trip (Ziemke et al., 2019) } \\
=\text { bet }_{\text {perf }}=6.0 \text { EUR per hour (Ziemke et al., } \\
2019)\end{array}$ \\
\hline SAV users & $\begin{array}{l}\text { trip-related fixed cost } \\
\text { daily profit for no longer owning a } \mathrm{CC} \\
\text { private time cost } \\
\text { user price (base fare) } \\
\text { total fare payments }\end{array}$ & $\begin{array}{l}c_{h}^{S A V u} \\
c_{o}^{S A V u} \\
C_{\text {fare }}^{S A V u}\end{array}$ & $\begin{array}{l}0 \text { EUR per trip } \\
5.3 \text { EUR (per SAV user who (i) used a CC in the } \\
\text { base case and (ii) has no other CC trip). In (Tab. } \\
\text { 8-32 Planco et al., 2015), for an electric vehicle, } \\
\text { i.e. a Citroen C-Zero, vehicle-specific fixed costs } \\
\text { (without costs for the driver) ["Feste Kosten (ohne } \\
\text { Lohn)"] are 1,930 EUR per year; divided by } 365 \\
\text { days per year results in } 5.3 \text { EUR per day. } \\
=c_{h}^{C C} .70 \% \text { (Litman, } 2017 \mathrm{~b} \text {; Childless et al., 2015) } \\
=4.2 \text { EUR per person-hour } \\
=0.35 \text { EUR per km (estimated user costs based } \\
\text { on Trommer et al. (2016) and Bösch et al. (2018)) } \\
\text { see Sec. } 3.3\end{array}$ \\
\hline SAV operator & $\begin{array}{l}\text { total congestion road charges } \\
\text { total fare revenues }\end{array}$ & $\begin{array}{l}C_{\text {toll }}^{S A V o} \\
C_{\text {fare }}^{S A V u}\end{array}$ & $\begin{array}{l}\text { see Sec. } 2.1 \\
\text { equal to the amount paid by the SAV users }\end{array}$ \\
\hline
\end{tabular}




\section{Results}

\subsection{Average tolls and fares}

Tab. 2 depicts the resulting average toll and fare per trip and per kilometer traveled for the SAV and CC mode. The SAV base fare amounts to $0.35 \mathrm{EUR} / \mathrm{km}$ and depending on the simulation experiment a dynamic congestion charge (see Sec. 2.1) is added to these costs. For CC users, the operating costs are set to 0.20 EUR per kilometer (see Tab. 1) and only in simulation experiment SAV-2, a dynamic congestion charge has to be paid. Low average CC toll payments per kilometer are explained by relatively uncongested, longdistance trips starting and/or ending outside of Berlin. The congestion charges depend on

Table 2: Tolls and fares paid by CC and SAV users (trip-based analysis)

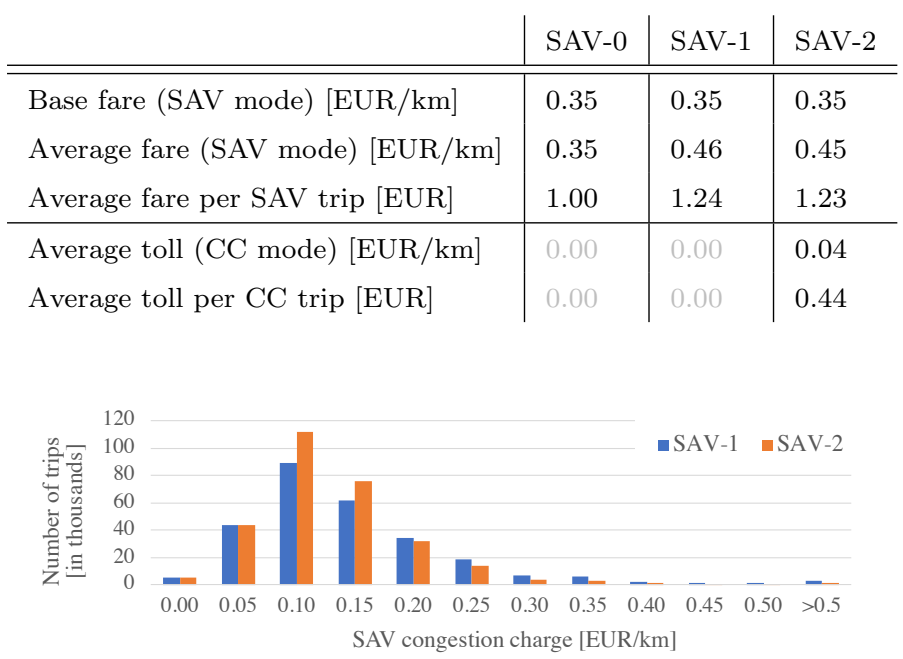

Figure 2: Trip frequency for the resulting SAV congestion charges

the level of traffic congestion. Consequently, during peak times and on heavily congested road segments, the congestion charge is at a higher level. Fig. 2 depicts the trip frequency for the resulting SAV congestion charges. For a few trips, SAV users only pay the base fare and the congestion charge is zero. For approximately $95 \%$ of all trips, the congestion charge ranges from $0.05 \mathrm{EUR} / \mathrm{km}$ to $0.30 \mathrm{EUR} / \mathrm{km}$. For some trips the congestion charge is even much higher and reaches up to a maximum of $7.16 \mathrm{EUR} / \mathrm{km}$ (Exp. SAV-1) or $5.03 \mathrm{EUR} / \mathrm{km}($ Exp. SAV-2). 


\subsection{Mode shift effects}

The aggregated mode shift effect is depicted in Fig. 3. For each simulation experiment,

Table 3: Modal split analysis

\begin{tabular}{l|l|l|l|l} 
& bc-0 & SAV-0 & SAV-1 & SAV-2 \\
\hline Total CC trip share [\%] & 43.2 & 42.5 & 42.6 & 39.4 \\
Total PT trip share [\%] & 14.0 & 13.6 & 13.7 & 14.8 \\
Total Bicycle trip share [\%] & 13.4 & 13.3 & 13.3 & 15.2 \\
Total Walk trip share [\%] & 20.2 & 19.6 & 19.7 & 19.8 \\
Total Ride trip share [\%] & 9.2 & 9.2 & 9.2 & 9.2 \\
Total SAV trip share [\%] & - & 1.8 & 1.5 & 1.6 \\
\hline SAV trip share within service area [\%] & - & 17.7 & 14.8 & 15.8 \\
SAV trips (upscaled to full population size) & - & 326,420 & 272,620 & 292,080
\end{tabular}

the mode-specific trip share is given taking into consideration all trips (i.e. trips inside and outside of Berlin). The overall low total SAV trip shares are explained by the small service area and relatively small number of SAV trips compared to the total trip number. With respect to a total of $1,847,310$ trips starting and ending within the SAV service area (see Fig. 1), the SAV trip share amounts to $17.7 \%$ in experiment SAV-0, $14.8 \%$ in experiment SAV-1 and $15.8 \%$ in experiment SAV-2.

Fig. 3 depicts the person-specific mode shift effects in two simulation experiments. The line width is proportional to the number of users that have switched from one mode to the other or that have used the same mode of transportation in both cases. All figures refer to the potential SAV users, i.e. individuals with at least one trip starting and ending inside the service area.

Comparing simulation experiment SAV-0 and bc-0 (Fig. 3a), the overall observation is that the SAV mode attracts users from all possible modes of transportation (CC, PT, bicycle, walk), in particular from the CC, walk and PT mode. A comparison of simulation experiment SAV-1 and SAV-0 (Fig. 3c) reveals that SAV pricing pushes users from the SAV mode to other modes. The simultaneous SAV and CC congestion pricing scheme pushes transport users from both the $\mathrm{CC}$ and SAV mode to other modes, in particular to the PT and bicycle mode. The disaggregated analysis reveals that there are always mode shift effects into both directions, e.g. from the $\mathrm{CC}$ to the PT mode and vice versa. Comparing experiment SAV-0 and bc-0, a closer look into the numbers reveals that there are slightly 


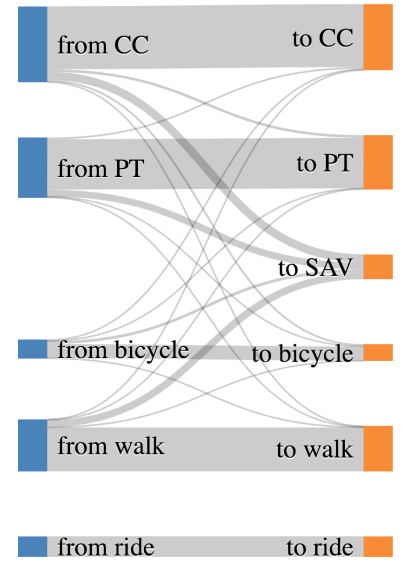

(a) bc- $0 \rightarrow$ SAV-0

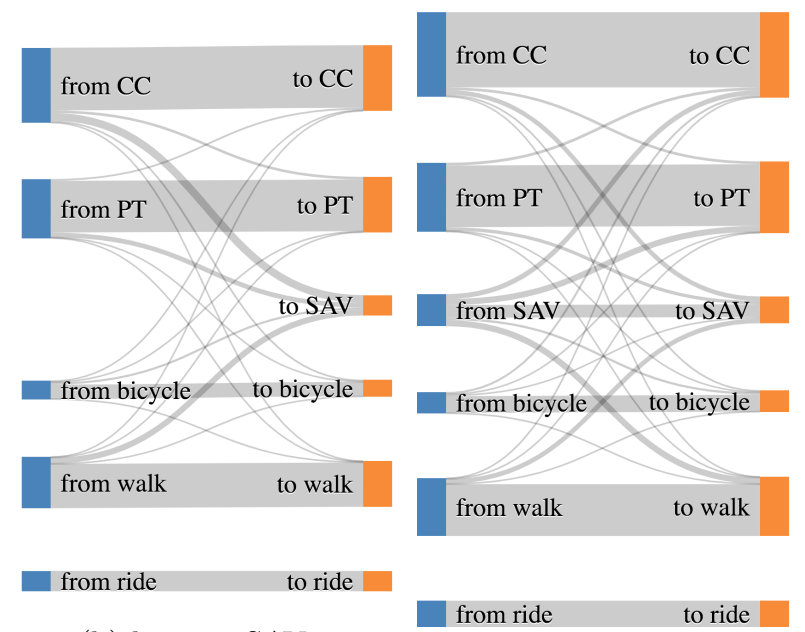

(b) bc- $0 \rightarrow$ SAV- 1

(c) SAV-0 $\rightarrow$ SAV-1

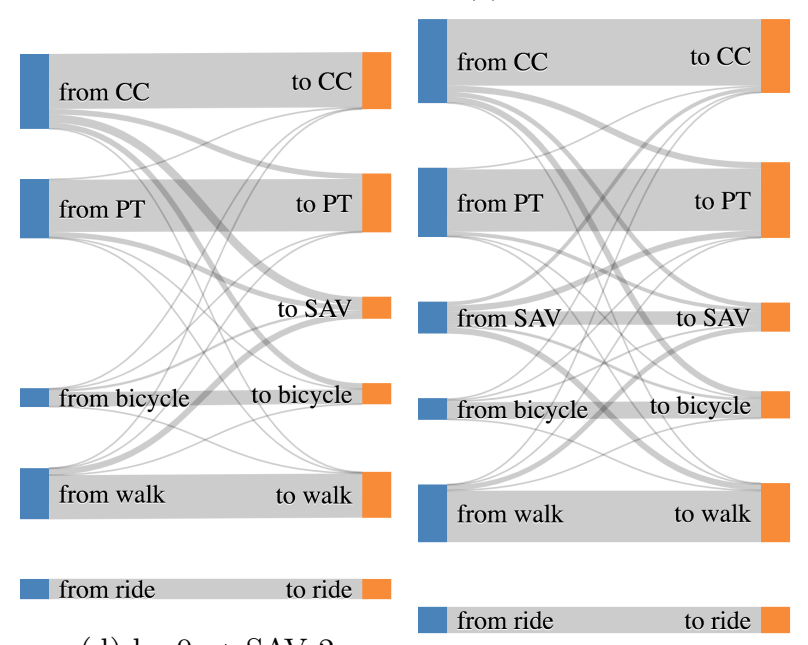

(d) bc- $0 \rightarrow$ SAV-2

(e) SAV-0 $\rightarrow$ SAV-2

Figure 3: Mode switch analysis (all trips by potential SAV users) 
more users switching from CC to PT and bicycle compared to the users switching from PT and bicycle to CC. This indicates that the SAV mode is not only attracting transport users from the $\mathrm{CC}$ mode but also makes the $\mathrm{CC}$ mode relatively less attractive and pushes towards the PT and bicycle mode. A comparison of Fig. 3c and Fig. 3e reveals the change in mode switch patterns in the different pricing experiments. Comparing experiment SAV1 and SAV-0 (Fig. 3c), the most dominant mode switch effect is from SAV (back) to CC as well as to PT and walk. In contrast, comparing experiment SAV-2 to SAV-0 (Fig. 3e), the most dominant mode switch effect from SAV to PT and walk. That is, the additional pricing of the $\mathrm{CC}$ mode, makes the $\mathrm{CC}$ mode less attractive for users switching from the SAV mode to alternative modes.

\subsection{Travel time}

For each mode switch effect described in the previous section, Fig. 4 depicts the change in average beeline speed. The beeline speed is computed as the beeline distance between the trip's origin and destination divided by the travel time. A first observation is that

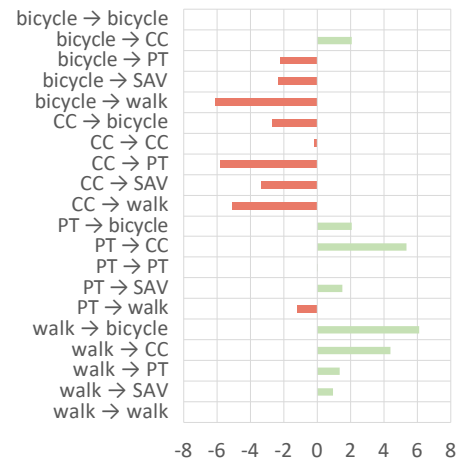

(a) bc- $0 \rightarrow$ SAV-0

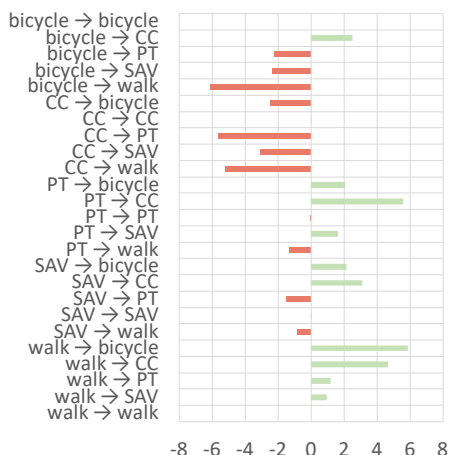

(b) SAV-0 $\rightarrow$ SAV-1

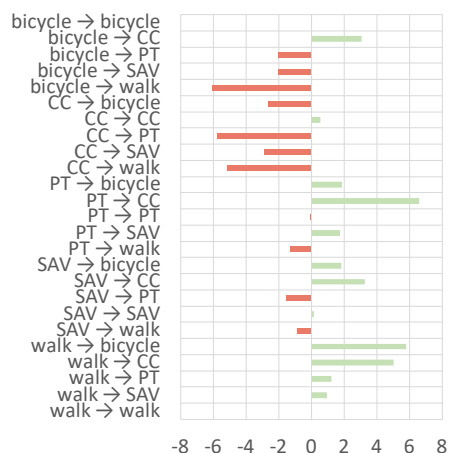

(c) SAV-0 $\rightarrow$ SAV-2

Figure 4: Change in average beeline speed per trip for each mode switch effect $[\mathrm{km} / \mathrm{h}]$; only potential SAV users

changes in the beeline speed are mainly related to the mode switch type, i.e. the currently and previously used mode of transportation. Transport users switching from the bicycle and CC mode to the SAV mode decrease their beeline speed, whereas, users switching from PT and walk to the SAV mode increase their travel speed (experiment SAV-0 vs. bc-0, Fig. 4a). Changes in beeline speed of transport users remaining within the same transport mode are much smaller compared to users switching between different modes. 
For users remaining within the CC and SAV mode, the change in average beeline speed and travel time per trip are provided in Tab. 4 and may be used as an indicator for the traffic congestion level. The introduction of the SAV mode is observed to increase the traffic

Table 4: Changes in average beeline speed and travel time per trip; transport users remaining within their transport modes; only potential SAV users

\begin{tabular}{l|lll} 
mode switch type & bc-0 $\rightarrow$ SAV-0 & SAV-0 $\rightarrow$ SAV-1 & SAV-0 $\rightarrow$ SAV-2 \\
\hline & \multicolumn{4}{|c}{ Change in average beeline speed $[\mathrm{km} / \mathrm{h}]$} \\
$\mathrm{CC} \rightarrow \mathrm{CC}$ & $-0.16(-1.13 \%)$ & $+0.02(+0.15 \%)$ & $+0.56(+4.03 \%)$ \\
$\mathrm{SAV} \rightarrow \mathrm{SAV}$ & - & $+0.02(+0.32 \%)$ & $+0.16(+2.30 \%)$ \\
\hline \hline & & Change in average travel time $[\mathrm{sec}]$ \\
$\mathrm{CC} \rightarrow \mathrm{CC}$ & $+16(+1.22 \%)$ & $-2(-0.14 \%)$ & $-65(-4.51 \%)$ \\
$\mathrm{SAV} \rightarrow \mathrm{SAV}$ & - & $-4(-0.41 \%)$ & $-25(-2.54 \%)$ \\
\hline \hline
\end{tabular}

congestion level (SAV-0 vs. bc-0). The pricing schemes counteract this effect and reduce the traffic congestion level compared to the unregulated SAV market (increase in beeline speed in SAV-1 vs. SAV-0 and SAV-2 vs. SAV-0). Applying the congestion charge to the SAV mode only (experiment SAV-1) yields a very small reduction in traffic congestion (increase in beeline speed below $1 \%$ for both the CC and SAV mode). In contrast, applying the congestion charge to both the SAV and CC mode (experiment SAV-2) yields a very strong reduction in traffic congestion.

Next, the change in average beeline distance of all potential SAV users is analyzed over all mode switch types. Introducing the SAV mode increases the beeline speed by 0.82 $\mathrm{km} / \mathrm{h}(+9.24 \%)$ compared to the base case (SAV-0 vs. bc-0). This may be explained by the mode shift effect from slow modes (e.g. walk and PT) to the much faster SAV mode. Simulation experiment SAV-1 reduces the beeline speed by $0.07 \mathrm{~km} / \mathrm{h}(-0.72 \%)$ compared to experiment SAV-0 since transport users are pushed (back) to slower modes. Simulation experiment SAV-2 increases the average beeline speed by $0.05 \mathrm{~km} / \mathrm{h}(+0.48 \%)$ compared to experiment SAV-0 which may be explained by the increase in overall system efficiency.

\subsection{Traffic volume}

Fig. 5 depicts the changes in daily traffic volume (sum of CC and SAV) per road segment. Overall, introducing the SAV mode (experiment SAV-0) increases the traffic volume in the inner-city area compared to the base case (see Fig. 5a). Charging a congestion charge from 


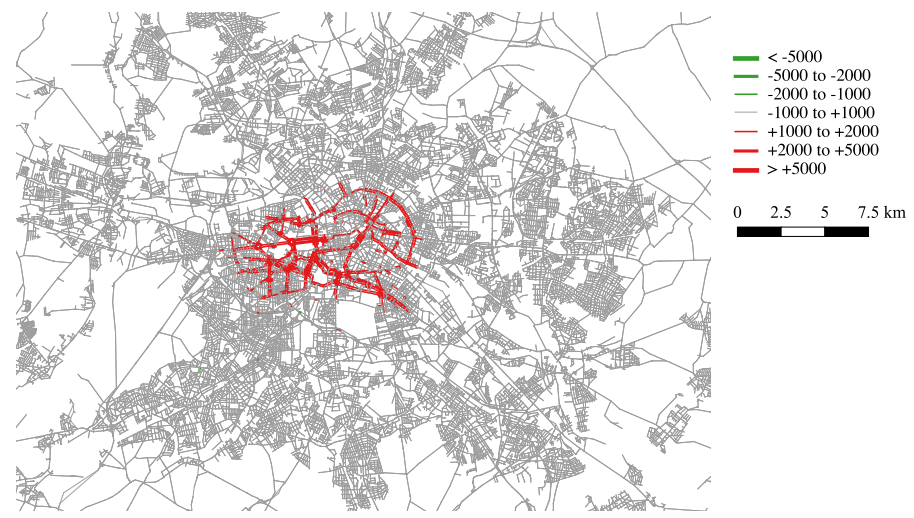

(a) Exp. SAV-0 vs. bc-0.

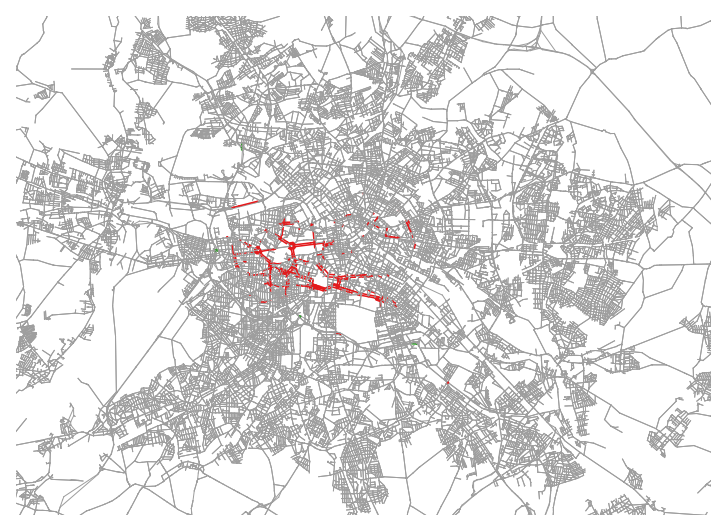

(b) Exp. SAV-1 vs. bc-0.

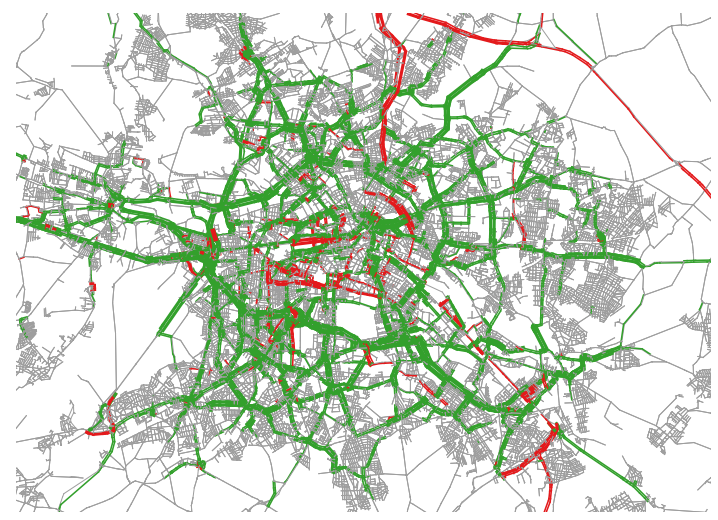

(d) Exp. SAV-2 vs. bc-0.

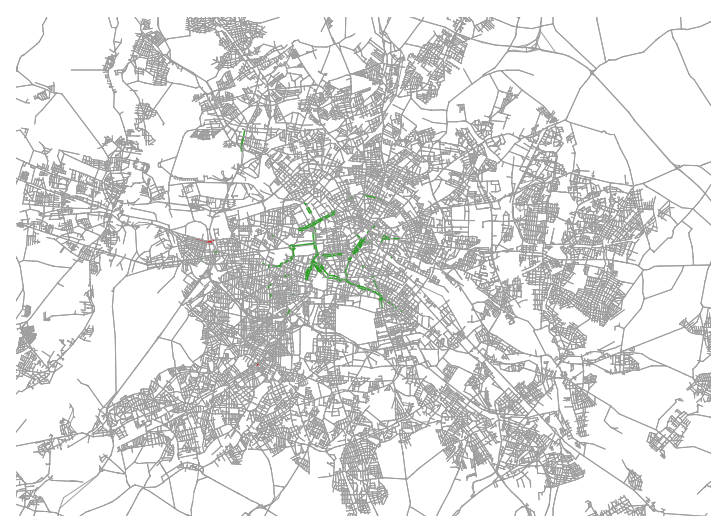

(c) Exp. SAV-1 vs. SAV-0.

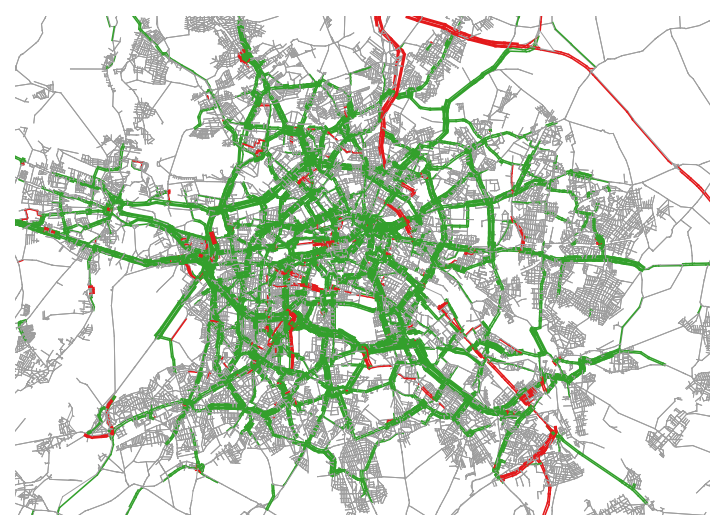

(e) Exp. SAV-2 vs. SAV-0

Figure 5: Change in daily traffic volume (sum of CC and SAV) per road segment

SAV users reduces this effect and fewer individuals use the SAV mode which translates into a reduced number of SAV vehicles in the service area compared to experiment SAV-0 (see Fig. 5b and 5c). Additionally applying the congestion charge to CC users yields a significant reduction in daily traffic volume on most road segments compared to the base 
case. However, on some road segments, in particular in the city center area, traffic volumes increase (see Fig. 5d and 5e). Fig. 6 investigates this effect in more detail and depicts the change in traffic volume for different vehicle types. This shows that the observed increase

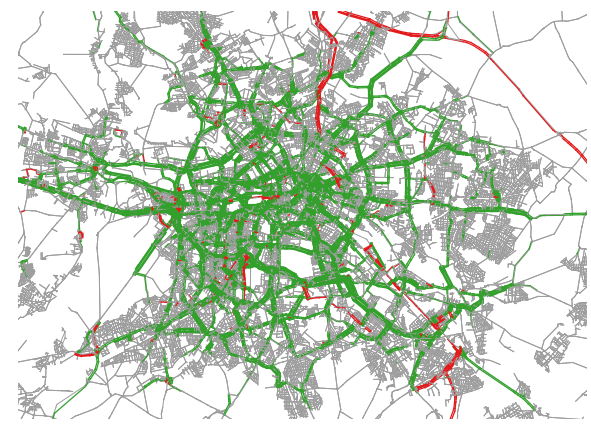

(a) Change in $\mathrm{CC}$

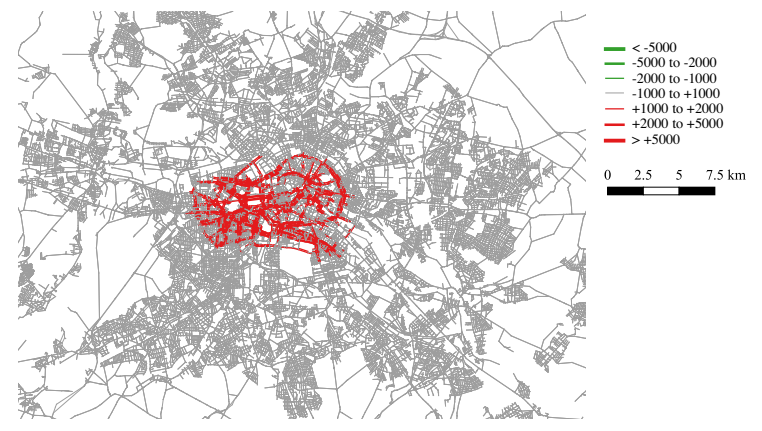

(b) Change in SAV

Figure 6: Change in traffic volume per vehicle type; Exp. SAV-2 vs. bc-0.

in daily traffic volume in the inner-city center area is caused by SAV operations. The number of $\mathrm{CC}$ are observed to decrease for most road segments, also in the inner-city center area which is explained by the overall reduction in CC users.

\subsection{SAV performance}

Fig. 7 depicts the SAV operation performance parameters during the course of the day. In all simulation experiments, throughout the day, approximately half of the SAV fleet

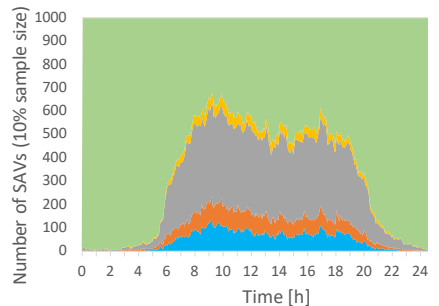

(a) Exp. SAV-0

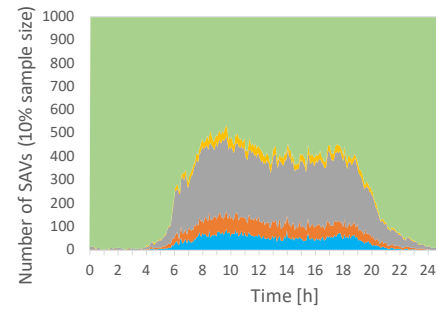

(b) Exp. SAV-1

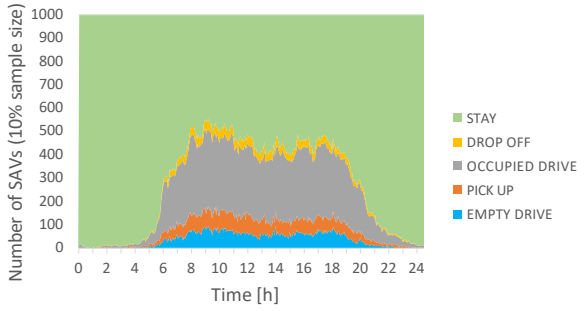

(c) Exp. SAV-2

Figure 7: SAV time profile: Number of SAVs (10\% sample size) per time of day. Green: stay and wait for a trip request. Yellow: passenger drop off. Gray: occupied drive. Orange: passenger pick up. Blue: empty drive.

is available and waits for a trip request. That is, there are no trip request rejections caused by capacity constraint effects and waiting times are rather short compared to a reduced fleet size. In simulation experiment SAV-0, the average waiting time per SAV 
trip amounts to $185 \mathrm{sec}$ and the average in-vehicle time per SAV trip amounts to 740 sec. A reduced number of SAV users and less traffic congestion translates into a decrease in average waiting time (169 sec in experiment SAV-1; $170 \mathrm{sec}$ in experiment SAV-2).

\subsection{System welfare}

Tab. 5 depicts the changes in system welfare compared to the base case (bc-0). System welfare is defined as the sum of the travel related user benefits, monetary payments and SAV operating costs. Environmental effects are separately analyzed in Sec. 4.7 and not accounted for in the aggregated welfare analysis. In all simulation experiments with SAV,

Table 5: Aggregated results: Change in system welfare; comparison with the base case; upscaled to full population size

\begin{tabular}{l|l|l|l} 
Change in... & SAV-0 vs. bc-0 & SAV-1 vs. bc-0 & SAV-2 vs. bc-0 \\
\hline \hline travel related user benefits (incl. tolls/fares) [k EUR] & 323.67 & 201.82 & -2440.20 \\
\hline monetary payments [k EUR] & 329.00 & 338.94 & 3590.01 \\
\hline change in SAV operating costs [k EUR] & 389.85 & 303.33 & 331.76 \\
\hline \hline system welfare [k EUR] & 262.81 & 237.44 & 818.06 \\
\hline \hline
\end{tabular}

system welfare increases compared to the base case (bc-0). In simulation experiment SAV-1, system welfare decreases compared to the unregulated SAV market (experiment SAV-0). Regulating both the CC and SAV market (simulation experiment SAV-2) yields the largest increase in system welfare.

\subsection{Environmental effects}

This section analyzes the air pollution, in particular nitrogen oxides $\left(N O_{x}\right)$ emissions and noise (day-evening-night index, $L_{d e n}$ ) effects caused by road traffic. The air pollution emission computation follows the methodology described in Hülsmann et al. (2011) and Kickhöfer et al. (2013). The computation approach accounts for vehicle characteristics (vehicle type, age, cubic capacity, fuel type etc.), dynamic attributes (parking duration, distance travelled, speed, traffic state) and road types are used to get the cold and warm emissions from HBEFA ${ }^{2}$ database. The computation of air pollution emissions is based on the assumption that all CC have combustion engines and all SAV are electric.

\footnotetext{
${ }^{2}$ Handbook Emission Factors for Road Transport', Version 3.2, see www.hbefa.net (INFRAS, 2010)
} 
For the propagation of air pollution to the the surrounding area, a Gaussian distance weighting function is used (Agarwal, 2017, Appendix A). The noise computation follows the methodology described in Kaddoura et al. (2017a) which is based on the German RLS-90 approach ('Richtlinien für den Lärmschutz an Straßen', FGSV, 1992) taking into account the traffic volume, the share of heavy goods vehicles and the speed level. For speed levels above $30 \mathrm{~km} / \mathrm{h}$, an electric vehicle is assumed to have an effect approximately similar to a vehicle with a combustion engine. Therefore, the applied noise computation does not differentiate between SAV and CC. The absolute environmental effect in the base case (experiment bc-0) is shown in Fig. 8. Overall, along the inner-city motorway as well
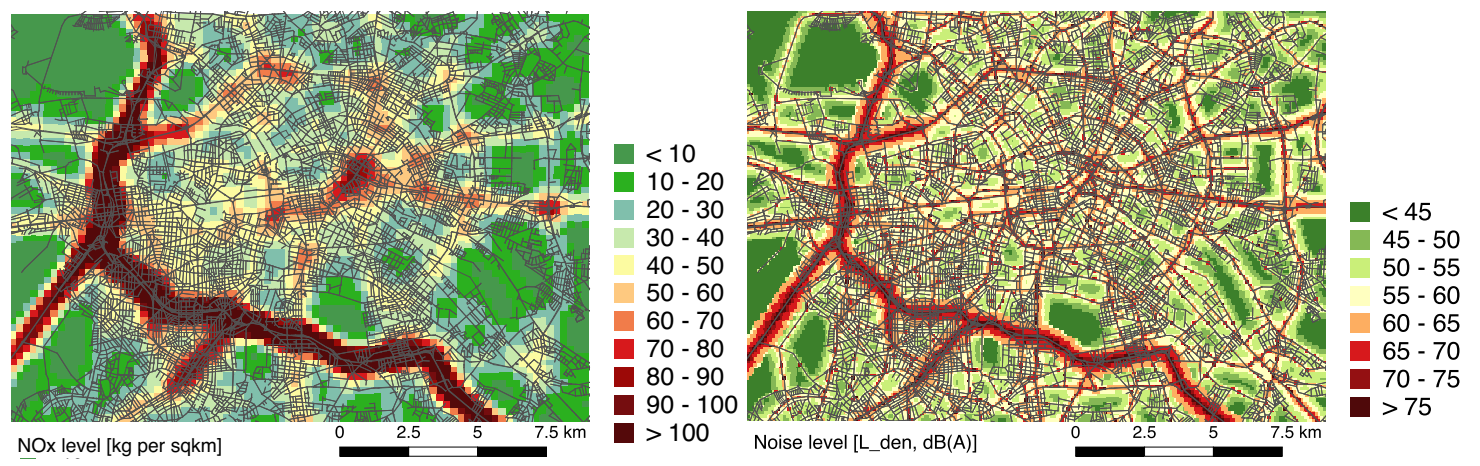

Figure 8: Absoulte $N O_{x}$ and noise $L_{\text {den }}$ levels; City center area

as main roads, absolute $N O_{x}$ and noise levels are much higher compared to areas along smaller roads.

Impact on air pollution Fig. 9 depicts the changes in $N O_{x}$ levels resulting from the different simulation experiments. In experiment SAV-0 some users are shifted from the CC mode to the electric SAV mode (see Sec. 4.2). Consequently, $N O_{x}$ levels are observed to decrease in the inner-city area (see Fig. 9a). In experiment SAV-1, a more expensive SAV mode decreases the number SAV users, thus, the previous effect is reduced (see Fig. 9b) and $N O_{x}$ levels slightly increase compared to experiment SAV-0 (see Fig. 9c). Additionally applying the congestion charge to CC users significantly reduces the air pollution levels in the entire Berlin area, in particular along the inner-city motorway and main roads as well as in the inner-city center area (see Fig. 9d and 9e).

Impact on noise Fig. 10 depicts the changes in noise $\left(L_{d e n}\right)$ levels resulting from the different simulation experiments. Therefore, the increase in traffic volume (see Fig. 5a) 


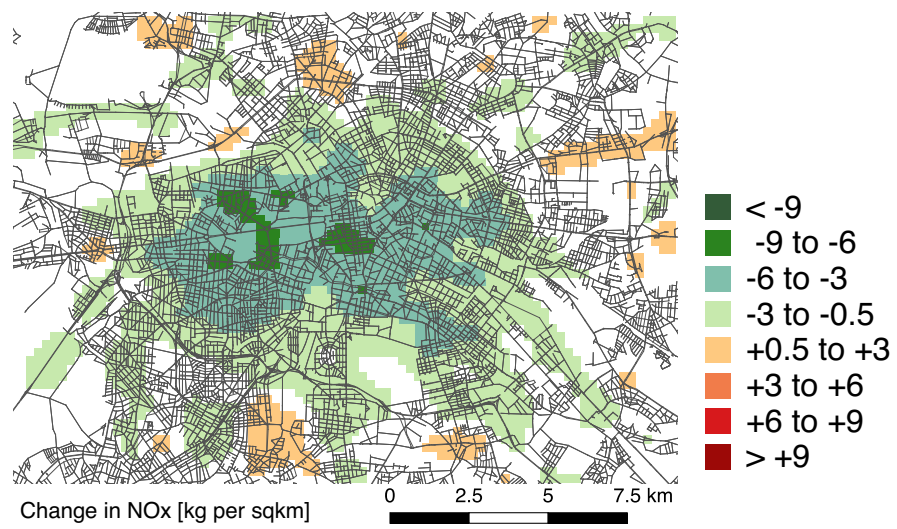

(a) Exp. SAV-0 vs. bc-0.

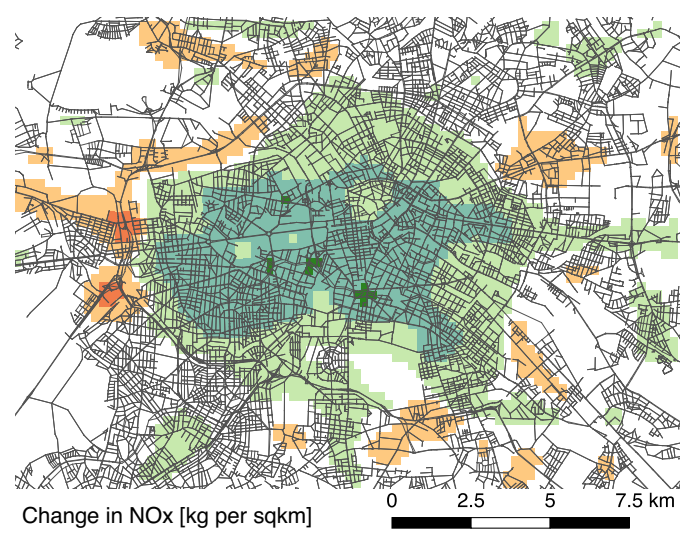

(b) Exp. SAV-1 vs. bc-0.

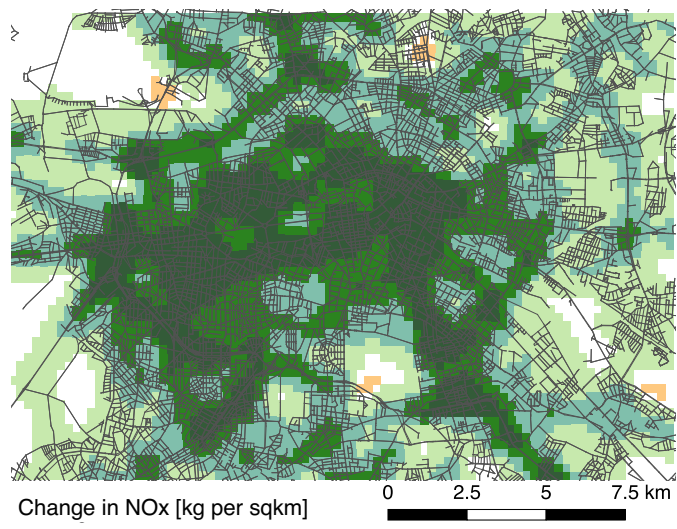

(d) Exp. SAV-2 vs. bc-0.

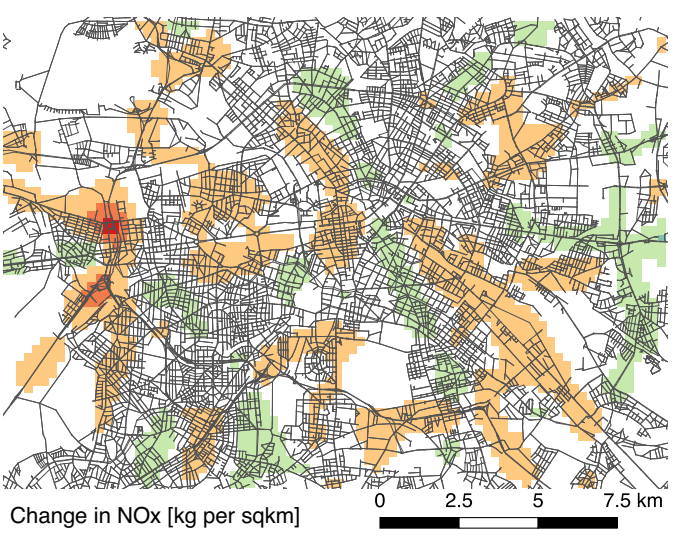

(c) Exp. SAV-1 vs. SAV-0.

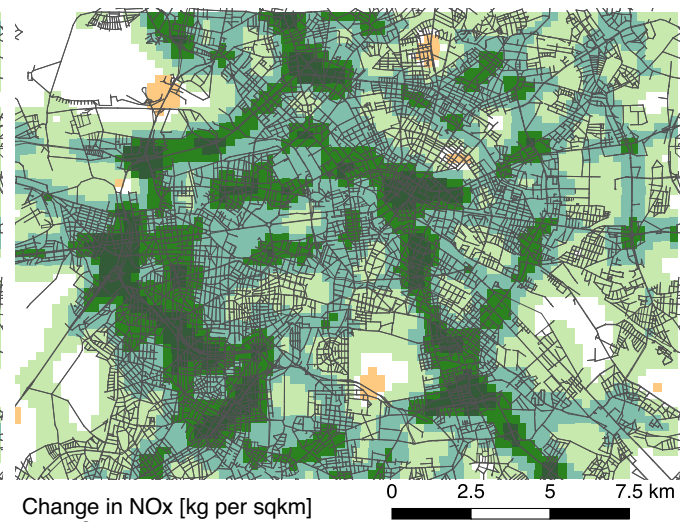

(e) Exp. SAV-2 vs. SAV-0.

Figure 9: Change in daily $N O_{x}$ levels [kg per sqkm]; City center area

translates into slightly higher noise levels in the inner-city Berlin area (experiment SAV-0 vs. bc-0; see Fig. 10a). The logarithmic scale of noise yields a much higher elasticity for roads with lower traffic volumes. Thus, experiment SAV-1 only has a minor effect on the noise levels and changes in noise levels compared to experiment SAV-0 are indiscernible 


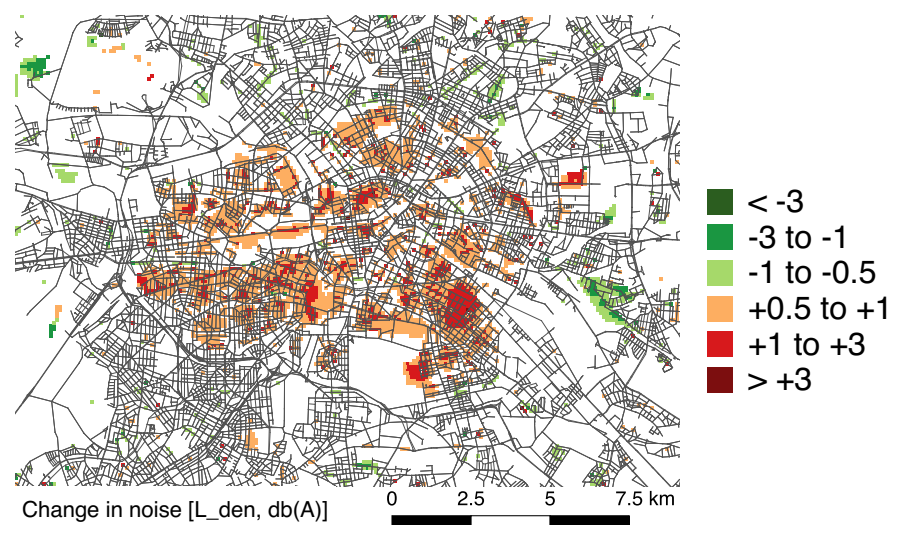

(a) Exp. SAV-0 vs. bc-0.

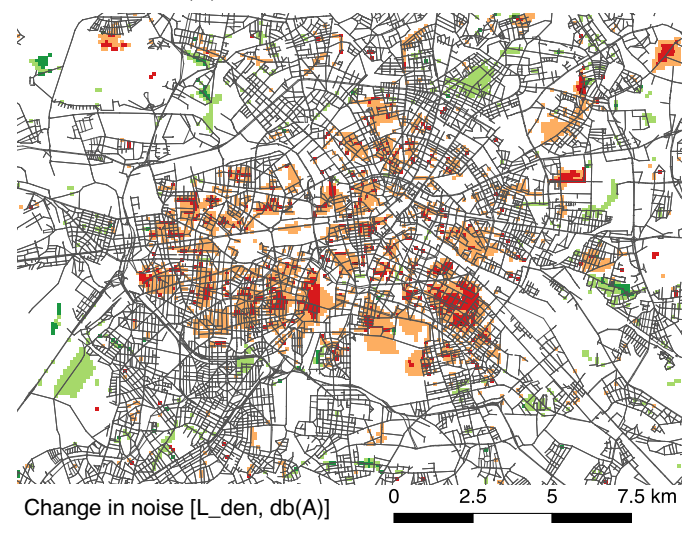

(b) Exp. SAV-1 vs. bc-0.

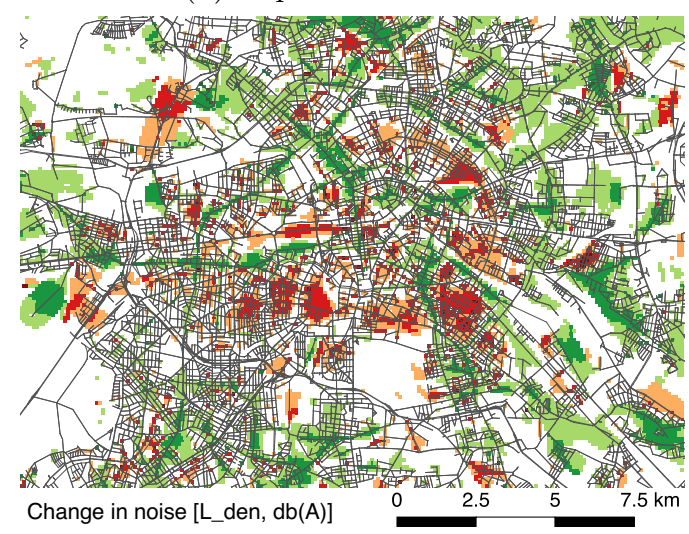

(d) Exp. SAV-2 vs. bc-0.

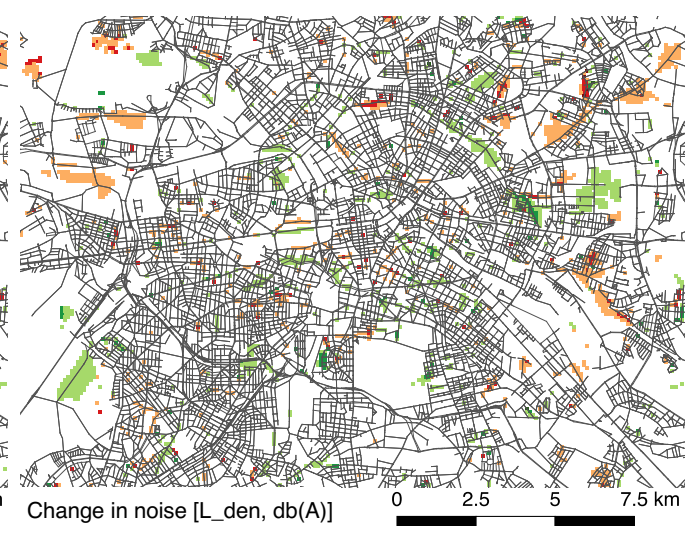

(c) Exp. SAV-1 vs. SAV-0.

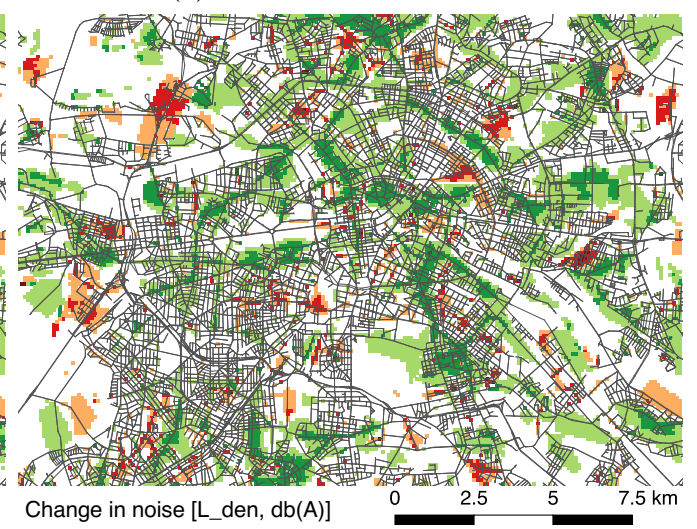

(e) Exp. SAV-2 vs. SAV-0.

Figure 10: Change in noise $\left(L_{d e n}\right.$; day-evening-night index $)$; City center area

(see Fig. 10b and 10c). The large reduction in CC users in experiment SAV-2 yields a strong reduction in noise levels compared to the base case (see Fig. 10d) and experiment SAV-0 (see Fig. 10e) along several road corridors. Nevertheless, the increase in noise resulting from the additional SAV traffic is only partly compensated and overall noise levels still increase along minor roads in the inner-city area (see Fig. 10d). 


\section{Discussion}

In this study, the applied pricing scheme only accounts for the traffic congestion externality. Further external effects such as air pollution and noise are analyzed, but not included into the pricing. This could be easily changed if of interest. Adding noise damage costs to the SAV pricing scheme for example would probably push traffic from minor roads in residential areas to major roads, to less densely populated areas, or to other modes of transportation (Kaddoura and Nagel, 2018).

The SAV fleet size is deliberately set to a very high level of 10,000 SAVs in order to avoid rejections of trip requests caused by fleet size constraint effects. As shown in previous studies, above a certain threshold value, changing the vehicle fleet size only yields a minor change in service quality, see e.g. Maciejewski and Bischoff (Fig. 5, demandsupply-balancing strategy, 2015) and Bischoff (Fig. 6.1, 2019). Thus, reducing the vehicle fleet size to the maximum level of simultaneously required vehicles $(5,000-6,000 \mathrm{SAVs}$, see Fig. 7) would not have a significant effect on the overall service quality and simulation outcome.

The applied German RLS-90 methodology does not explicitly account for speed levels below $30 \mathrm{~km} / \mathrm{h}$ where engine noise dominates over rolling and aerodynamic noise and, thus, the vehicle engine type may have a significant effect on the noise level. Considering SAVs to be electric, the observed increase in noise levels caused by SAV traffic (see Fig. 10a) may be overestimated, in particular along smaller roads with speed levels below or around $30 \mathrm{~km} / \mathrm{h}$. Further research is required to develop or apply a more suitable noise computation approach in order to correctly account for electric vehicles and predict the impact on the environmental noise.

In the existing base scenario of the Greater Berlin area, daily mode-specific fixed costs such as for owning a car or a public transit annual ticket are not explicitly accounted for. In order to compensate for this, a reward for no longer owning a car was instead implemented for the present study (see Tab. 1). Future base scenarios should rather include a separate

parameter for daily fixed cost if a certain mode is used at all. For the CC mode, the daily cost of owning a vehicle may approximately be set to 5.3 EUR (Tab. 8-32, Planco et al., 2015, see also Tab. 1 in the present study). For the public transit mode, daily monetary costs may be set to the daily share of an annual ticket, e.g. 2.1 EUR (761.00 EUR annual 
ticket fare Berlin; divided by 365 days per year).

\section{Conclusion and outlook}

In this study, congestion pricing is applied to the shared autonomous vehicle (SAV) transport mode. Several simulation experiments (see Sec. 3.3) are carried out in order to investigate the effects of different pricing setups on the overall transport system and the environment. In experiment SAV-0, SAV users only have to pay the base fare of $0.35 \mathrm{EUR} / \mathrm{km}$. In experiment SAV-1, SAV users additionally have to pay a congestion charge. In experiment SAV-2, both the SAV and conventional (driver-controlled) private car (CC) users have to pay a congestion charge.

For SAV-0, where SAV users only pay the base fare of $0.35 \mathrm{EUR} / \mathrm{km}$ and there is no congestion charge added to the user costs, the model predicts an SAV share of $17.7 \%$ within the service area (inner-city Berlin area, see Fig. 1). This number is higher compared to Trommer et al. (2016) who estimate an SAV trip share of $10 \%$ by the year 2035 , however, referring to all of Germany. Thus, a higher SAV trip share in an urban area seems plausible. With congestion pricing, the SAV trip share amounts to $14.8 \%$ (experiment SAV-1; congestion pricing for SAV users only) and $15.8 \%$ (experiment SAV-2; congestion pricing for SAV and CC users) of all trips within the service area (inner-city center area).

Introducing the SAV mode yields an increase in traffic in the in the inner-city Berlin area. Consequently, the level of traffic congestion increases. Since SAV are assumed to be electric and $\mathrm{CC}$ to have a combustion engine, a mode shift from CC to the SAV mode translates into lower air pollution concentrations in the inner-city area. In contrast, noise levels slightly increase in the inner-city area, in particular along minor roads in residential areas.

Applying a congestion charge to the SAV mode (experiment SAV-1) only slightly reduces the level of traffic congestion compared to the case where SAV users only pay the base fare. A significant reduction in travel time is only obtained in the case where the congestion charge is applied to both the SAV and CC mode (experiment SAV-2). The latter pricing scheme also significantly reduces air pollution levels in the entire Berlin area. Along certain corridors, noise levels are observed to decrease, however, still increase along smaller roads 
in residential areas.

Overall, this study highlights the importance to control both, the SAV and CC mode, in order to improve a city's transport system. Charging congestion prices from both SAV and CC users (experiment SAV-2) results in the largest increase in system welfare and strongest reduction in environmental effects. Regulating no or only one transport mode (experiments SAV-0 and SAV-1) increases system welfare compared to the base case (bc-0), however, results in a lower system welfare compared to experiment SAV-2. Charging congestion cost fees from SAV users but not from CC users (experiment SAV-1) even results in a lower system welfare compared to the unregulated SAV and CC mode (experiment SAV-0).

This study recommends pricing policies to develop integrated pricing schemes for all modes of transportation, in particular the $\mathrm{CC}$ and the SAV mode. A fare above operating costs will decrease the number of transport users switching from bicycle and walk to the SAV mode which may be a desired effect. However, without an increase in costs for CC users, a higher SAV fare also pushes users from the SAV to the CC mode. Furthermore, to tackle the increase in traffic volume on minor roads in residential areas, SAV operators or regulators should re-think door-2-door service, and instead possibly define virtual pick-up points that are located conveniently for users and well accessible for SAV operators. Both Berlkönig by BVG in Berlin and MOIA in Hamburg and Hannover show tendencies in this direction.

Future studies will address the model's sensitivity regarding changes in cost parameters, e.g. the daily profit for no longer owning a $\mathrm{CC}\left(r_{d a y}^{S A V u}\right)$ and the value of travel time savings for using the SAV $\left(c_{h}^{S A V u}\right)$, as well as SAV operation parameters, i.e. the service area and the SAV fleet size. Furthermore, existing studies on regulative measures, e.g. a ban on private cars in the city center area (Bischoff and Maciejewski, 2016b), should be extended and combined with different pricing schemes as well as analyzed with regard to mode switch effects and the environmental impact.

\section{Acknowledgements}

A previous version of this paper was presented at the 6th Symposium of the European Association for Research in Transportation (hEART 2017) in Haifa, Israel (September, 12th 2017). The authors wish to thank William (Billy) Charlton for providing the visualization tool used to generate Fig. 3. 


\section{References}

Agarwal, A. Mitigating negative transport externalities in industrialized and industrializing countries. PhD thesis, TU Berlin, Berlin, 2017.

Ahrens, G.-A. Endbericht zur Verkehrserhebung Mobilität in Städten - SrV 2008 in Berlin. Technical report, Technische Universität Dresden, 2009. http://www.stadtentwicklung.berlin.de/verkehr/politik_planung/ zahlen_fakten/download/2_SrV_endbericht_tudresden_2008_berlin.pdf.

Arnott, R., A. de Palma, and R. Lindsey. A structural model of peak-period congestion: A traffic bottleneck with elastic demand. The American Economic Review, 83(1):161-179, 1993. ISSN 00028282. URL http: //www.jstor.org/stable/2117502.

Bischoff, J. Mobility as a Service and the transition to driverless systems. PhD thesis, TU Berlin, Berlin, 2019. in preparation.

Bischoff, J. and M. Maciejewski. Simulation of City-wide Replacement of Private Cars with Autonomous Taxis in Berlin. Procedia Computer Science, 83:237-244, 2016a. ISSN 1877-0509. doi: 10.1016/j.procs.2016.04.121.

Bischoff, J. and M. Maciejewski. Autonomous taxicabs in Berlin - a spatiotemporal analysis of service performance. Transportation Research Procedia, 19:176-186, 2016b. doi: 10.1016/j.trpro.2016.12.078.

Burghout, W., P.-J. Rigole, and I. Andreasson. Impacts of Shared Autonomous Taxis in a Metropolitan Area. In Transportation Research Board 94th Annual Meeting, number 15-4000, 2015.

Bösch, P. M., F. Becker, H. Becker, and K. W. Axhausen. Cost-based analysis of autonomous mobility services. Transport Policy, 64:76-91, May 2018. doi: 10.1016/j.tranpol.2017.09.005.

Childless, S., B. Nichols, B. Charlton, and S. Coe. USING AN ACTIVITY-BASED MODEL TO EXPLORE POSSIBLE IMPACTS OF AUTOMATED VEHICLES. Annual Meeting Preprint 15-5118, Transportation Research Board, Washington, D.C., Jan. 2015.

Fagnant, D. and K. Kockelman. Preparing a nation for autonomous vehicles: opportunities, barriers and policy recommendations. Transportation Research Part A, 77:167-181, 2015. doi: /10.1016/j.tra.2015.04.003.

Fagnant, D. J. and K. M. Kockelman. The travel and environmental implications of shared autonomous vehicles, using agent-based model scenarios. Transportation Research Part C: Emerging Technologies, 40:1-13, 2014. ISSN 0968-090X. doi: 10.1016/j.trc.2013.12.001. URL http://www.sciencedirect.com/science/article/pii/ S0968090X13002581.

Fagnant, D. J. and K. M. Kockelman. Dynamic ride-sharing and fleet sizing for a system of shared autonomous vehicles in Austin, Texas. Transportation, pages 1-16, 2016. ISSN 1572-9435. doi: 10.1007/s11116-016-9729-z. URL http://dx.doi.org/10.1007/s11116-016-9729-z.

FGSV. Richtlinien für den Lärmschutz an Straßen (RLS), Ausgabe 1990, Berichtigte Fassung. Forschungsgesellschaft für Straßen- und Verkehrswesen, 1992. URL http://www.fgsv.de.

Harb, M., Y. Xiao, G. Circella, P. L. Mokhtarian, and J. L. Walker. Projecting travelers into a world of selfdriving vehicles: estimating travel behavior implications via a naturalistic experiment. Transportation, 45(6): 1671-1685, Nov. 2018. ISSN 1572-9435. doi: 10.1007/s11116-018-9937-9. URL https://doi.org/10.1007/ s11116-018-9937-9. 
Harris, M. Uber Could Be First to Test Completely Driverless Cars in Public. IEEE Spectrum, 14.09.2015, 2015. URL http://spectrum.ieee.org/cars-that-think/transportation/self-driving/ uber-could-be-first-to-test-completely-driverless-cars-in-public.

Horni, A., K. Nagel, and K. W. Axhausen, editors. The Multi-Agent Transport Simulation MATSim. Ubiquity, London, 2016. doi: 10.5334/baw.

Hsu, J. GM and Lyft Team Up for Robot Taxi Service. IEEE Spectrum, 04.01.2016, Jan. 2016. URL http://spectrum.ieee.org/cars-that-think/transportation/self-driving/ gm-and-lyft-team-up-for-robot-taxi-service.

Hülsmann, F., R. Gerike, B. Kickhöfer, K. Nagel, and R. Luz. Towards a multi-agent based modeling approach for air pollutants in urban regions. In Conference on "Luftqualität an Straßen", pages 144-166. Bundesanstalt für Straßenwesen, FGSV Verlag GmbH, 2011. ISBN 978-3-941790-77-3. Also VSP WP 10-15, see http://www.vsp. tu-berlin.de/publications.

infas and DLR. Mobilität in Deutschland 2008 - Ergebnisbericht. Schlussbericht für Forschungsprojekt FE Nr. 70.801/2006, Institut für angewandte Sozialwissenschaft, Deutsches Zentrum für Luft- und Raumfahrt, 2010. URL http://daten.clearingstelle-verkehr.de/223/.

INFRAS. Handbook Emission Factors for Road Transport 3.1. Technical report, INFRAS Zurich Switzerland, 2010. URL www.hbefa.net. See http://www.hbefa.net.

Kaddoura, I. Marginal Congestion Cost Pricing in a Multi-Agent Simulation: Investigation of the Greater Berlin Area. Journal of Transport Economics and Policy, 49(4):560-578, 2015.

Kaddoura, I. and K. Nagel. Simultaneous internalization of traffic congestion and noise exposure costs. Transportation, 45(5):1579-1600, 2018. doi: 10.1007/s11116-017-9776-0.

Kaddoura, I. and K. Nagel. Congestion pricing in a real-world oriented agent-based simulation context. Research in Transportation Economics, 2019. doi: 10.1016/j.retrec.2019.01.002.

Kaddoura, I., B. Kickhöfer, A. Neumann, and A. Tirachini. Optimal public transport pricing: Towards an agentbased marginal social cost approach. Journal of Transport Economics and Policy, 49(2):200-218, 2015. Also VSP WP 13-09, see http://www.vsp.tu-berlin.de/publications. Awarded as the Best PhD Student Paper at hEART 2013.

Kaddoura, I., L. Kröger, and K. Nagel. An activity-based and dynamic approach to calculate road traffic noise damages. Transportation Research Part D: Transport and Environment, 54:335-347, 2017a. ISSN 1361-9209. doi: $10.1016 /$ j.trd.2017.06.005.

Kaddoura, I., L. Kröger, and K. Nagel. User-specific and dynamic internalization of road traffic noise exposures. Networks and Spatial Economics, 17(1):153-172, 2017b. doi: 10.1007/s11067-016-9321-2.

Kickhöfer, B., F. Hülsmann, R. Gerike, and K. Nagel. Rising car user costs: comparing aggregated and geo-spatial impacts on travel demand and air pollutant emissions. In Vanoutrive, T. and A. Verhetsel, editors, Smart Transport Networks: Decision Making, Sustainability and Market structure, NECTAR Series on Transportation and Communications Networks Research, pages 180-207. Edward Elgar Publishing Ltd, 2013. ISBN 978-1-78254832-4. doi: 10.4337/9781782548331.00014.

Kraus, M. Discomfort externalities and marginal cost transit fares. Journal of Urban Economics, 29:249-259, 1991. 
Litman, T. Autonomous Vehicle Implementation Predictions. Victoria Transport Policy Institute, 2017a. URL http://www.vtpi.org/avip.pdf.

Litman, T. Transportation Cost and Benefit Analysis II - Travel Time Costs. Technical report, Victoria Transport Policy Institut, 2017b.

Liu, J., K. M. Kockelman, P. M. Boesch, and F. Ciari. Tracking a system of shared autonomous vehicles across the Austin, Texas network using agent-based simulation. Transportation, 44(6):1261-1278, Nov. 2017. ISSN 1572-9435. doi: 10.1007/s11116-017-9811-1. URL https://doi.org/10.1007/s11116-017-9811-1.

Maciejewski, M. Dynamic Transport Services. In Horni et al. (2016), chapter 23. doi: 10.5334/baw.

Maciejewski, M. and J. Bischoff. Large-scale Microscopic Simulation of Taxi Services. Procedia Computer Science, 52:358-364, 2015. ISSN 1877-0509. doi: 10.1016/j.procs.2015.05.107. URL http://www.sciencedirect.com/ science/article/pii/S1877050915009072.

Maciejewski, M., J. Bischoff, S. Hörl, and K. Nagel. Towards a Testbed for Dynamic Vehicle Routing Algorithms. In Bajo, J., Z. Vale, K. Hallenborg, A. P. Rocha, P. Mathieu, P. Pawlewski, E. Del Val, P. Novais, F. Lopes, N. D. Duque Méndez, V. Julián, and J. Holmgren, editors, Highlights of Practical Applications of Cyber-Physical MultiAgent Systems: International Workshops of PAAMS 2017, Porto, Portugal, June 21-23, 2017, Proceedings, pages 69-79. Springer International Publishing, 2017. ISBN 978-3-319-60285-1. doi: 10.1007/978-3-319-60285-1.

Martinez, L. M., G. H. A. Correia, and J. M. Viegas. An agent-based simulation model to assess the impacts of introducing a shared-taxi system: an application to Lisbon (Portugal). Journal of Advanced Transportation, 49 (3):475-495, July 2014. doi: 10.1002/atr.1283. URL http://dx.doi.org/10.1002/atr.1283.

Pigou, A. The Economics of Welfare. MacMillan, New York, 1920.

Planco, ITP, and TUBS. Grundsätzliche Überprüfung und Weiterentwicklung der Nutzen-Kosten-Analyse im Bewertungsverfahren der Bundesverkehrswegeplanung. Endbericht FE Projekt Nr. 960974/2011, Planco GmbH, Intraplan Consult GmbH, TU Berlin Service GmbH, 2015. Im Auftrag des BMVI. Auch VSP WP 14-12, see http://www.vsp.tu-berlin.de/publications.

Sharon, G., M. W. Levin, J. P. Hanna, T. Rambha, S. D. Boyles, and P. Stone. Network-wide adaptive tolling for connected and automated vehicles. Transportation Research Part C: Emerging Technologies, 84:142-157, 2017. doi: $10.1016 /$ j.trc.2017.08.019.

Spieser, K., K. Treleaven, R. Zhang, E. Frazzoli, D. Morton, and M. Pavone. Toward a systematic approach to the design and evaluation of automated mobility-on-demand systems: A case study in Singapore. In Road Vehicle Automation, pages 229-245. Springer, 2014. URL http://hdl.handle.net/1721.1/82904.

Trommer, S., V. Kolarova, F. E., L. Kröger, B. Kickhöfer, T. Kuhnimhof, B. Lenz, and P. Phleps. Autonomous Driving: The Impact of Vehicle Automation on Mobility Behaviour. Institute for Mobility Research (ifmo), 2016.

Truong, L. T., C. De Gruyter, G. Currie, and A. Delbosc. Estimating the trip generation impacts of autonomous vehicles on car travel in Victoria, Australia. Transportation, 44(6):1279-1292, Nov. 2017. ISSN 1572-9435. doi: 10.1007/s11116-017-9802-2. URL https://doi.org/10.1007/s11116-017-9802-2.

Turvey, R. and H. Mohring. Optimal Bus Fares. Journal of Transport Economics and Policy, 9(3):280-286, 1975.

Verhoef, E. T. and K. A. Small. Product Differentiation on Roads: Constrained Congestion Pricing with Heterogeneous Users. Journal of Transport Economics and Policy, 38(1):127-156, 2004. 
Vickrey, W. Congestion Theory and Transport Investment. The American Economic Review, 59(2):251-260, 1969.

Ziemke, D., I. Kaddoura, and K. Nagel. The MATSim Open Berlin Scenario: A multimodal agent-based transport simulation scenario based on synthetic demand modeling and Open Data. VSP Working Paper 19-01, TU Berlin, Transport Systems Planning and Transport Telematics, 2019. URL http://www.vsp.tu-berlin.de/ publications. 